\title{
Catch and Fish-loss Model for Vertical Longline Fishing with Particular Emphasis on Injury of Unharvested Fish
}

\author{
Tatsuro Matsuoka, ${ }^{* 1}$ John Kasu, ${ }^{* 2}$ and Henry Nagaleta*2 \\ ${ }^{*}$ Faculty of Fisheries, Kagoshima University, Shimoarata, Kagoshima 890, Japan \\ ${ }^{*}$ Faculty of Science, the University of Papua New Guinea, P.O. Box 320, University, \\ National Capital District, Papua New Guinea
}

(Received December 26, 1994)

\begin{abstract}
Underwater fish loss in vertical longline fishing was assessed with emphasis on injury of unharvested fish. Two series of experimental fishing were conducted in tropical deep water. The capture process was statistically modeled and ratios of contact, hooking and fish-loss, which includes escape of hooked fish and breaking branch lines, were found to depend on the gear-soaking time or hook height from the sea bed. A simulation using a model estimated that fish loss was 1.07 times more than the catch when the tested line maximized the catch under the tested condition. The fish-loss/catch ratio increases rapidly with longer soaking of the gear. To reduce fish loss, vertical longlines with fewer hooks at short vertical intervals must be used to maximize the catch at a short soaking. In richer fishing grounds, the optimum soaking period is shorter, the catch per line increases and fish loss decreases, therefore, only a small number of lines is needed to maximize the catch. The development of fishing with an increasing number of hooks may accelerate fish loss as resources dwindle. The technical transfer of longlining to developing countries whose fishing grounds are mostly under-developed must be reevaluated.
\end{abstract}

Key words: vertical longline, capture process, fish-loss, fish injury, mortality, technical transfer, developing country

The development of fishing technology for the conservation of marine resources and the environment is of modern and world-wide interest. The assessment of unharvested fish injured while fishing is a primary issue in recent fishing management. In order to study this issue, it is necessary to study not only capture but also other under-water fishing results. The authors have studied the capture mechanisms in vertical longline fishing, and have attempted to clarify the successive steps and results through the capture process on the basis of field experiments, ${ }^{1-4)}$ where problems of unharvested and injured fish were precautioned. ${ }^{3,4)}$

In the vertical longline experiment previously reported, fishing results were classified into bait retention, bait loss, cut branch-line, broken hook or catching fish. The study derived a probability model of fish-hook contact in view of hook positions and soaking time, however, bait theft by unhooked fish and bait removal by a fish once hooked and subsequently escaped could not be distinguished. These were both observed as bait-loss hooks. This was reflected in two limitations of the study:

(1) Ratios at the capture steps subsequent to contact in comparison to the phenomenon immediately prior to each step in the capture process could not be clarified, and

(2) Fish-loss which comprised of both fish escape and line break could not be quantified.

These limitations reduced the usefulness of the probability model to represent fish loss in the capture process.

An additional experiment was therefore conducted to distinguish bait theft and fish escape. This enabled the probability of fish loss to be assessed. This paper describes the relationship between catch and fish-loss in terms of hook positions and gear-soaking time in vertical longline fishing. The feasibility of longlining for resource management and technical transfer is also discussed.

\section{Materials and Methods}

\section{Model of Capture Process in Vertical Longline Fishing}

The model of the capture process in vertical longline fishing was slightly modified in order to specify fish-loss (Fig. 1). The fish-hook/bait interaction which includes bait theft, fish escape after hooking, broken line/hook, and catching fish is defined as contact. Some of the contacted fish thieve bait, while others are hooked. A certain number of hooked fish escape by removing the hook and others are partly dislocated by breaking the branch line, where either the snood or hook is broken by the fish. If neither escape nor branch-line break occurs, the fish is caught. Fish loss, including escape and breaking branch lines, is assumed to injure the unharvested fish.

The above process has been proved to occur at probabilities dependent on the gear-soaking time and/or hook height from the sea bed, where hydrographic and biological externalities and gear design remain constant. $\left.{ }^{4}\right)$

\section{Experiment and Fishing Gear}

Two series of experimental fishing for deep-water snappers, mainly Etelis coruscans and E. calbunculus, conducted outside the barrier reef off Port Moresby in Papua New Guinea, are dealt with in the present paper. The principal data were from Experiment 1, which was previously reported together with information on the fishing ground, fishing gear, and caught species. ${ }^{4)}$ Experiment 2 was conducted in 


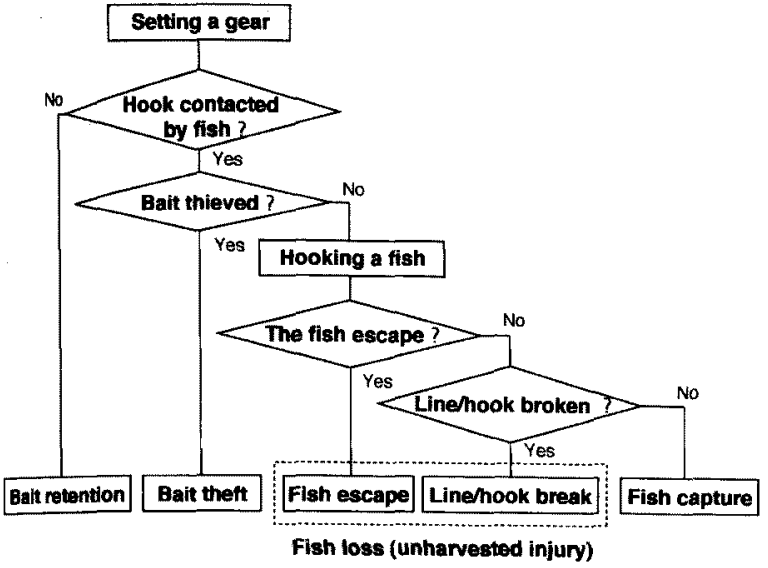

Fig. 1. Schematic diagram of capture process for vertical longline.

order to discriminate bait theft and fish escape, which had both been observed in one category of bait loss in Experiment 1 .

The vertical longline used in Experiment 2 was slightly changed for the above purpose. The arrangement of eight mutsu hooks at $1.8 \mathrm{~m}$ intervals was unchanged, however, an individual gear consisted of four branch lines each of different sizes of polyamide monofilaments, either $\# 45$ (normal) as a whole or partly \#8. The latter was intended to be cut when a fish was hooked but to let the bait be thieved by unhooked fish. They were located on either odd- or even-numbered positions along a center line. The branch lines made as above are referred to as $\mathrm{L}$ - and $\mathrm{S}$ branch lines. Experiment 2 maintained other factors the same as in Experiment 1, with the exception of relatively longer soaking to increase the number of fish-hook contacts.

The results on L-branch lines were recorded as in Experiment 1 , while $S$-lines were recorded as bait retention, bait theft or cut line, of which the recorded numbers were represented by $Q_{i}, Q_{t}$ and $Q_{a}$. The bait theft and cut line on S-lines were respectively thought to be equivalent to bait theft without being hooked and hooking when normal lines were used.

Hereafter, the values represented by $Q$-symbols relate to Experiment 2, while apostrophes indicate cumulate values of the two experiments.

\section{Data Analysis}

The contact ratios, $R_{c}{ }^{4)}$ derived in the previous paper were also used in this study as:

$$
R_{c}=1-\exp \left\{-0.0501 h^{-1.16} \cdot t\right\}
$$

where $h$ represents a distance $(m)$ from the sea bed to each hook along a center line and $t$, soaking time ( $\mathrm{min}$ ).

The hooking ratios, $R_{h}$, were calculated from the record on S-lines in Experiment 2 as:

$$
R_{h}=Q_{a} /\left(Q_{t}+Q_{a}\right)=Q_{a} / Q_{c}
$$

where $Q_{c}$ represents the number of contacts on S-lines in Experiment 2. According to the number of contacts, $N_{c}$, in Experiment 1 and $R_{h}$ above, the number of hookings, $N_{h}^{\prime}$, in Experiment 1 was estimated in order to divide the ob- served bait loss, $N_{l}$, in Experiment 1 into bait theft, $N_{l}^{\prime}$, and escape, $N_{e}^{\prime}$ as:

$$
\begin{aligned}
& N_{h}^{\prime}=N_{c} \cdot R_{h} \\
& N_{t}^{\prime}=N_{c}-N_{h}^{\prime} \\
& N_{e}^{\prime}=N_{l}-N_{t}^{\prime}
\end{aligned}
$$

The fish-loss ratios, $R_{l}^{\prime}$, were derived as:

$$
R_{l}^{\prime}=\left(N_{e}^{\prime}+N_{b}\right) / N_{h}^{\prime}
$$

where $N_{b}$ is the observed number of line breaks in Experiment 1. Although fish escape and line break are different phenomena in the capture process, the mechanism and sequence for the two to appear in the process were not clarified and there is no need to segregate them for the purpose of the present study.

Given the three ratios at the major diversion steps, or $R_{c}, R_{h}$ and $R_{i}^{\prime}$, the values of contact, $E_{c}$, hooking, $E_{h}^{\prime}$, fishloss, $E_{l}^{\prime}$, and fish catch, $E_{f}^{\prime}$ against the number of set hooks, $N_{s}$, are simulated as:

$$
\begin{aligned}
& E_{c}=N_{s} \cdot R_{c} \\
& E_{h}^{\prime}=N_{s} \cdot R_{c} \cdot R_{h} \\
& E_{l}^{\prime}=N_{s} \cdot R_{c} \cdot R_{h} \cdot R_{l}^{\prime} \\
& E_{f}^{\prime}=N_{s} \cdot R_{c} \cdot R_{h} \cdot\left(1-R_{l}^{\prime}\right)
\end{aligned}
$$

\section{Results}

\section{Ratios at Steps in Capture Process}

A total of 97 longlines were recorded with soaking for $80 \mathrm{~min}$ to $140 \mathrm{~min}$, with a mean of $110 \mathrm{~min}$, in Experiment 2, on which $387 \mathrm{~L}$ - and $386 \mathrm{~S}$-branch lines were examined respectively (Table 1). The contact ratios at hooks on Llines were compared to these calculated by Equation (1) for $110 \mathrm{~min}$ of soaking (Fig. 2). No differences were found at the $95 \%$ significant level, therefore, Experiment 2 was judged to have been conducted under conditions equivalent to those of Experiment 1. The contact ratios from S-

\begin{tabular}{|c|c|c|c|c|c|c|c|c|c|c|}
\hline \multirow{2}{*}{ Lines } & \multirow{2}{*}{ Status } & \multicolumn{8}{|c|}{ Number of results on each hook } & \multirow{2}{*}{ Tota } \\
\hline & & 1 & 2 & 3 & 4 & 5 & 6 & 7 & 8 & \\
\hline \multirow[t]{3}{*}{ L-line } & Recorded & 49 & 48 & 49 & 48 & 49 & 48 & 48 & 48 & 387 \\
\hline & Contact & 44 & 39 & 25 & 19 & 12 & 11 & 10 & 6 & \\
\hline & Contact ratio & .90 & .81 & .51 & .40 & .25 & .23 & .21 & .13 & \\
\hline \multirow[t]{6}{*}{ S-line } & Recorded & 48 & 49 & 48 & 49 & 48 & 49 & 47 & 48 & 386 \\
\hline & Contact & 44 & 31 & 23 & 17 & 15 & 12 & 12 & 9 & \\
\hline & Bait theft & 24 & 12 & 8 & 6 & 4 & 3 & 4 & 2 & \\
\hline & Cut line & 20 & 19 & 15 & 11 & 11 & 9 & 8 & 7 & \\
\hline & Contac & .92 & .63 & .48 & .35 & .31 & .24 & .26 & .19 & \\
\hline & Hooking ratio & .45 & .61 & .65 & .65 & .73 & .75 & .67 & .78 & \\
\hline
\end{tabular}
lines (Fig. 2) also showed no significant difference compared to both those from L-lines and those calculated with Equation (1), with the exception of that from L-lines at hook \#2. The S-lines were, therefore, assessed to have been set under conditions identical to Experiment 1 and to have functioned approximately similar to the L-lines as far as fish-hook contacts were concerned.

Hooking ratios, $R_{h}$, were obtained from the observed

Table 1. Fishing results on L- and S-lines in Experiment 2 


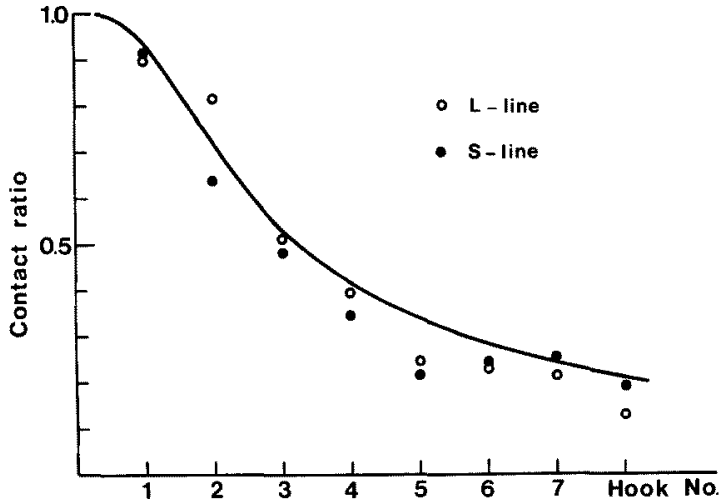

Fig. 2. Comparison of catch ratios observed on L- and S-lines in Experiment 2 (open and closed circles) and its graph for $110 \mathrm{~min}$ of soaking derived for Equation (1) from Experiment 1.

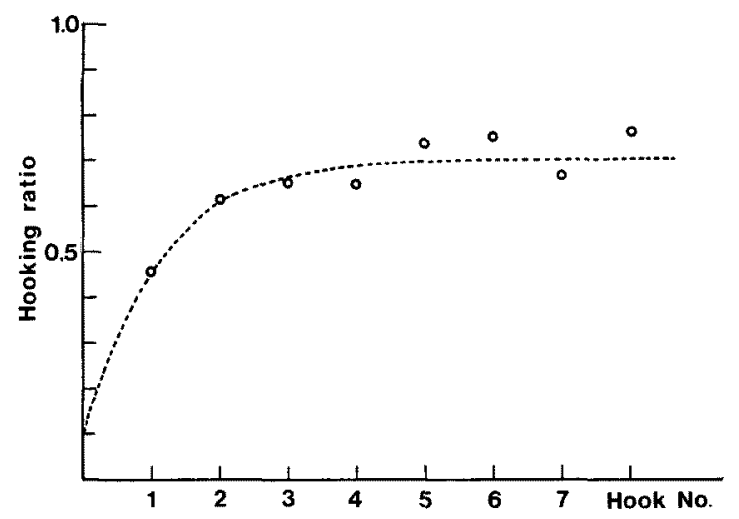

Fig. 3. Hooking ratios, $R_{h}$, obtained from Experiment 2 and graph of Equation (11). number of cut lines, $Q_{a}$, and contacts, $Q_{c}$, on S-lines in Experiment 2 (Table 1, Fig. 3). The ratios appeared to be relatively constant for most hook positions, with the exception of a lower ratio on hook \#1. The hooking ratio was represented as a function of hook position from the sea bed by iteration as:

$$
R_{h}=0.70-0.62 \exp (-0.52 h)
$$

where soaking time was not taken into account because the discrimination between bait theft and hooking was thought to occur at the instance of contact.

On the basis of Equation (3), the number of hookings, $N_{h}^{\prime}$, in Experiment 1 was estimated from the observed number of contacts, $N_{c}$, in Experiment 1 and Equation (11), where the results from 40-min soaking were excluded because of the small number of contacts and phenomena in the following steps. Subsequently, on the basis of Equations (4) and (5), the estimated number of escapes, $N_{e}^{\prime}$, in Experiment 1 was derived from the estimated number of hookings, $N_{h}^{\prime}$, and the observed number of bait losses, $N_{l}$, in Experiment 1 (Table 2).

Since no particular relationship was found between the fish-loss ratios, $R_{i}^{\prime}$, calculated from the above numbers, $N_{e}^{\prime}, N_{b}$, and $N_{h}^{\prime}$ on Equation (6) and positions of hooks, the fish-loss ratio was represented as a function of soaking time as (Fig. 4):

$$
R_{t}^{\prime}=1-\exp (-0.0112 t)
$$

Both the number of hookings and fish-losses estimated for Experiment 1 involved secondary values, therefore, the analytical results were hardly verified by the experimental values. The observed numbers of catches were, therefore, compared to those estimated by Equation (10) with Equations (1), (11), and (12) (Fig. 5). Despite comparatively less consistency, which was ascribed to accumulated statistical

\begin{tabular}{|c|c|c|c|c|c|c|c|c|c|}
\hline \multirow{2}{*}{ Soaking time } & \multirow{2}{*}{ Status } & \multicolumn{8}{|c|}{ Number of results on each hook } \\
\hline & & 1 & 2 & 3 & 4 & 5 & 6 & 7 & 8 \\
\hline \multirow[t]{5}{*}{60 min } & Contact $\left(N_{c}\right)$ & 41 & 34 & 19 & 13 & 12 & 11 & 11 & 8 \\
\hline & Hooking $\left(N_{h}^{\prime}\right)$ & 18.7 & 20.6 & 12.6 & 8.9 & 8.3 & 7.7 & 7.1 & 5.6 \\
\hline & Escape $\left(N_{e}^{\prime}\right)$ & 9.7 & 7.6 & 4.6 & 4.9 & 4.3 & 3.7 & 3.1 & 3.6 \\
\hline & Line break $\left(N_{b}\right)$ & 2 & 1 & 2 & 1 & 0 & 0 & 1 & 0 \\
\hline & Catch $\left(N_{f}\right)$ & 7 & 12 & 6 & 3 & 4 & 4 & 3 & 2 \\
\hline \multirow[t]{5}{*}{$80 \mathrm{~min}$} & Contact $\left(N_{c}\right)$ & 73 & 66 & 41 & 36 & 28 & 18 & 18 & 13 \\
\hline & Hooking $\left(N_{h}^{\prime}\right)$ & 33.4 & 39.9 & 27.2 & 24.7 & 19.4 & 12.6 & 12.6 & 9.1 \\
\hline & Escape $\left(N_{e}^{\prime}\right)$ & 16.4 & 23.9 & 13.2 & 12.7 & 11.4 & 5.6 & 5.6 & 4.1 \\
\hline & Line break $\left(N_{b}\right)$ & 6 & 6 & 3 & 1 & 1 & 1 & 2 & 2 \\
\hline & Catch $\left(N_{f}\right)$ & 11 & 10 & 11 & 11 & 7 & 6 & 5 & 3 \\
\hline \multirow[t]{5}{*}{$100 \mathrm{~min}$} & Contact $\left(N_{c}\right)$ & 55 & 41 & 37 & 23 & 17 & 14 & 16 & 10 \\
\hline & Hooking $\left(N_{h}^{\prime}\right)$ & 25.1 & 24.8 & 24.5 & 15.8 & 11.8 & 9.8 & 11.2 & 7.0 \\
\hline & Escape $\left(N_{e}^{\prime}\right)$ & 12.1 & 10.8 & 8.5 & 6.8 & 5.8 & 3.8 & 6.2 & 3.0 \\
\hline & Line break $\left(N_{b}\right)$ & 6 & 5 & 8 & 4 & 4 & 2 & 1 & 1 \\
\hline & Catch $\left(N_{f}\right)$ & 7 & 9 & 8 & 5 & 3 & 4 & 4 & 3 \\
\hline \multirow[t]{5}{*}{$120 \mathrm{~min}$} & Contact $\left(N_{c}\right)$ & 52 & 43 & 32 & 27 & 20 & 19 & 12 & 12 \\
\hline & Hooking $\left(N_{h}^{\prime}\right)$ & 23.8 & 26.0 & 21.2 & 18.5 & 13.9 & 13.3 & 8.4 & 8.4 \\
\hline & Escape $\left(N_{e}^{\prime}\right)$ & 9.8 & 14.0 & 10.2 & 6.5 & 6.9 & 5.3 & 4.4 & 4.4 \\
\hline & Line break $\left(N_{b}\right)$ & 8 & 5 & 3 & 5 & 2 & 2 & 2 & 2 \\
\hline & $\operatorname{Catch}\left(N_{f}\right)$ & 6 & 7 & 8 & 7 & 5 & 6 & 2 & 2 \\
\hline
\end{tabular}

Table 2. Cumulative results from Experiment 1 and 2 


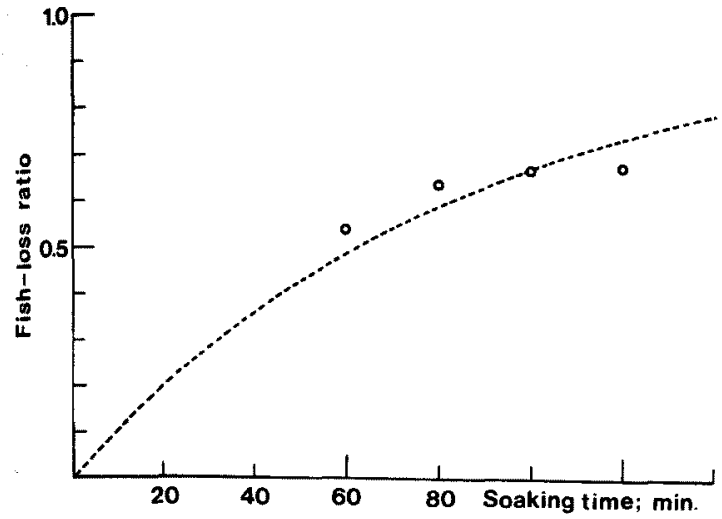

Fig. 4. Fish-loss ratio, $R_{l}^{\prime}$, estimated cumulatively from Experiment 1 and 2 and graph of Equation (12).

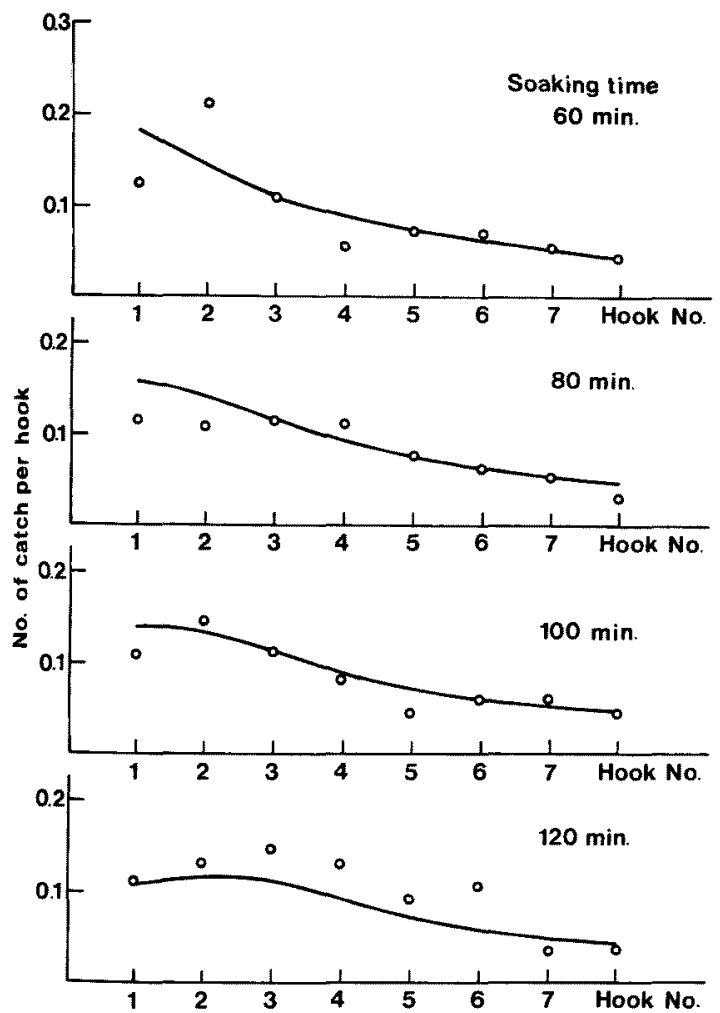

Fig. 5. Observed numbers of catch per hook and graphs of simulated numbers in Experiment 1.

errors at successive steps, they both indicated identical trends of:

(1) high ratios of catch at lower hooks when soaked for a short time,

(2) decreasing ratios of catch at lower hooks with increasing soaking time, and

(3) relatively high levels of catch on medium-positioned hooks with successively increasing soaking time.

\section{Simulation}

On the basis of application of the obtained ratios, $R_{c}, R_{h}$, and $R /$ to Equation from (7) to (10), the contact, hooking, fish loss, and catch on each hook were simulated under the

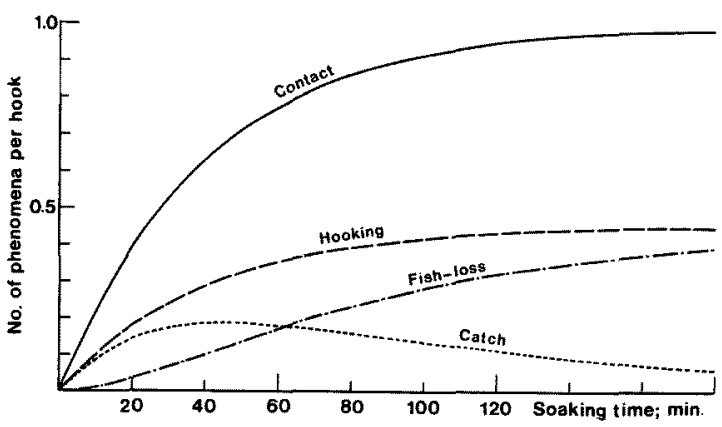

Fig. 6. Simulated results of fishing on No. 1 hook under experimental conditions, which represent the contact-retention model.

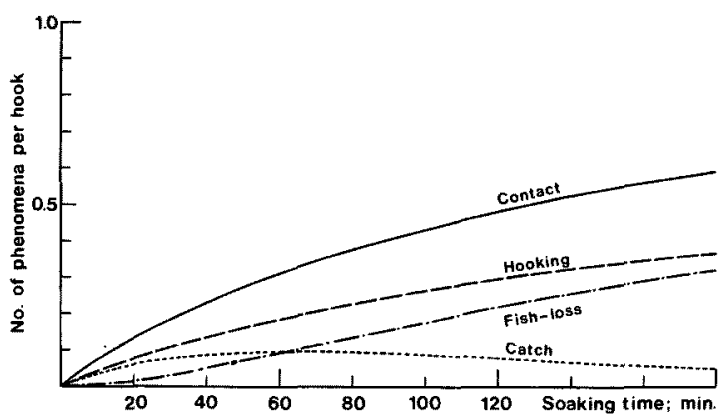

Fig. 7. Simulated results of fishing on average hook under experimental conditions, which represent the contact-retention model.

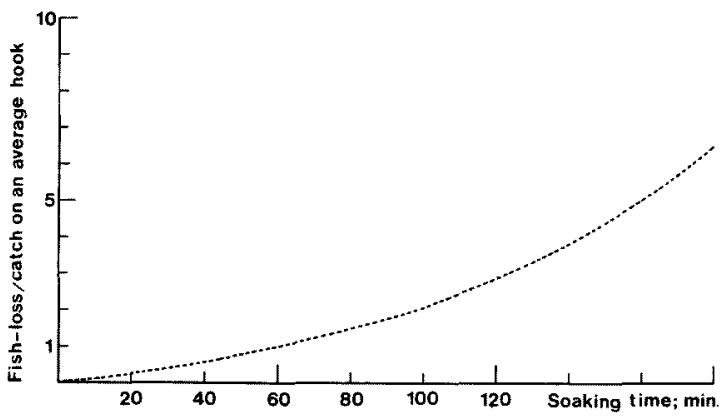

Fig. 8. Simulated ratio of fish-loss to catch on average hook under experimental conditions.

experimental conditions, and the most distinctive examples on hook \#1 are illustrated (Fig. 6). It was clearly indicated that fish retention from contact through hooking and fish loss resulted in catch, which was maximized at its optimum soaking time and gradually decreased by longer soaking.

Simulated results for an average of the experimental eight hooks are illustrated in Fig. 7. The contact-retention relationship was also clearly demonstrated with a wider range of catch mode. The decreasing number of catch after its mode and increasing number of fish loss with increasing soaking time were distinctive.

The ratio between the simulated numbers of fish loss and catch is illustrated in Fig. 8, where fish loss was 1.07 times more than catch for $65 \mathrm{~min}$ soaking, which is the optimum to maximize the catch under the experimental conditions. The fish-loss/catch ratio increases rapidly with lon- 
ger soaking and may even exceed two or even gneater when the gear was soaked longer. This may arise easily in commercial fishing because of an unremarkable slow decrease of catch over a long time after peaking, in comparison to the apparent increase during short soaking, as illustrated in Fig. 7.

In order to find ways to reduce fish loss, details of catch and fish loss were simulated. One maximum then descending catch were common among hooks (Fig. 9), while higher maxima of expected catch appeared on lowerpositioned hooks with shorter soaking. On the other hand, expected fish loss increased continuously with soaking time (Fig. 10). Although the expected fish loss on each hook must level off, it seems to increase relatively linearly within the simulated time. This suggests that fish loss can be reduced by fishing gear and method maximizing the catch with a short soaking time, and this is enabled by lower-positioned hooks.

Another simulation was carried out to assess the feasibility of the gear in fishing grounds of different resource status. The constant in the exponent in Equation (1) reflects the probabilities of contact positively, therefore, it must also be positively correlated with resource density in a fishing ground provided the gear design and target species remain constant. The constant was varied around the value obtained in the tested fishing ground, 0.0501 , in order to examine changes in the optimum soaking time and the numbers of catch and fish loss per line expected at the optimum soaking (Fig. 11). The result indicated that a greater catch per line with lesser fish loss could be achieved by shorter optimum soaking time where the constant was

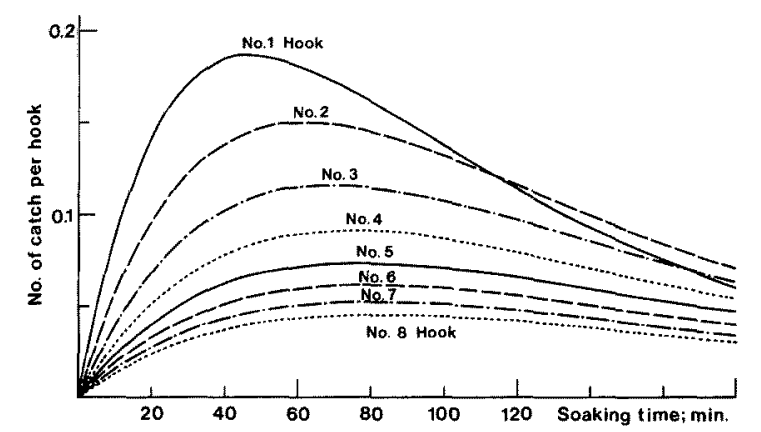

Fig. 9. Simulated numbers of catch per hook on different hooks under experimental conditions.

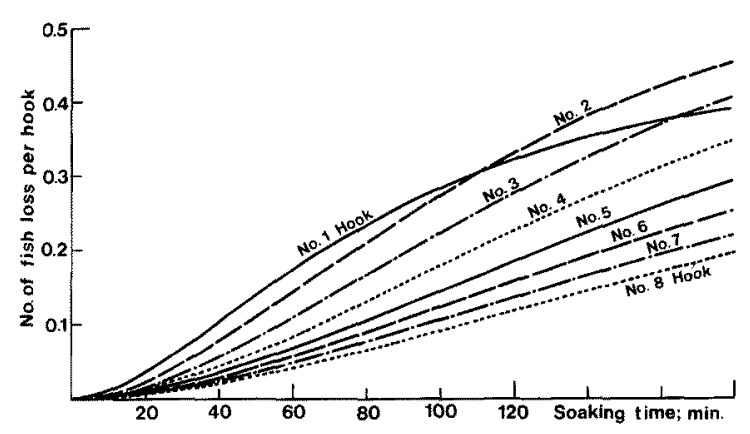

Fig. 10. Simulated numbers of fish loss per hook on different hooks under experimental conditions.

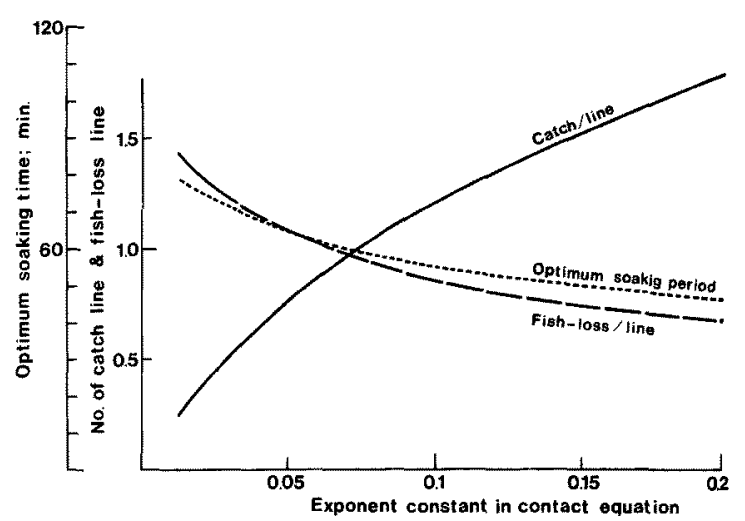

Fig. 11. Simulated numbers of catch and fish loss per line and optimum soaking time under various resource conditions which are represented by different values of the constant in the exponent of Equation (1).

greater. This implies that the gear must be soaked shorter in richer fishing grounds to increase the catch per line and decrease fish loss, while a prolonged optimum soaking time in poorer fishing ground is followed by a decreased catch per line and higher level of fish loss.

\section{Discussion}

Decreasing catches after reaching a maximum with increasing soaking time have been attributed to various factors other than fish loss in early research. Yamaguchi and Kobayashi ${ }^{5)}$ attributed the phenomenon in tuna longline to possible changes in feeding behavior of fish and decreasing effectiveness of baits during long soaking times. Hiraya$\mathrm{ma}^{6}$ attributed the phenomenon also in tuna longlining to drop out of baits, where drop out of hooked fish was omitted from factors in his proposal of an analytical model of capture mechanism. Shimamura and Soeda ${ }^{7}$ attributed the phenomenon in tuna longlining to deformation of lines due to long soaking. The possible effect of drop out of hooked fish was proposed by Ogura et al., ${ }^{8}$ and Arimoto et $a l .{ }^{9)}$ stressed the need to consider drop out of hooked fish on the basis of their model of capture mechanism of coastal bottom longlining. Arimoto ${ }^{109}$ added data which supported the above findings, however, no capture model to integrate fish-loss and catch has been developed. The authors modeled the decrease of catch observed in vertical longlining using the 'contact retention model' proposed in the previous paper. $\left.{ }^{4}\right)$ The model is further confirmed by the present result. According to Fig. 6 and 7, catch must possess such a trend under all circumstances. Since the probability of accumulated contact moves exponentially towards unity and hooking levels off in a certain proportion to contact, catch as retention reaches a maximum once, then decreases with longer soaking as far as fish loss increases with time. This trend is accelerated when fishloss phenomenon delays after hooking. All the above preconditions are applicable to most set line fishing gear, so the 'contact-retention model' should be applicable without respect to other external factors.

The time requised to maximize the number of catch is considered to be the optimum soaking time currently, however, increasing fish loss must be taken into account. 
Although ratios of injury and mortality among dislocated fish has not been documented well, catch-and-release studies for recreational fishery may give certain implications. Muoneke and Childress ${ }^{11)}$ described a mortality of up to $70 \%$ for Scienidae fishes, a higher mortality for fish angled by single, barbed, and baited hooks around the gills and stomachs and possible long-term suffering. Although the majority of data is from experiments on pole- and-line fishing for fresh water species, injury and, consequently, mortality of lost fish is surely not marginal in commercial longlining where fish are usually observed to swallow hooks deep as above. The present simulation suggests that there are ways to reduce fish loss or potential fish injury. The most important factor to achieve the above must be to modify gear to shorten the optimum soaking period, thus reducing fish loss. The simulated solution that catch is maximized on lower-positioned hooks is convincing. In other words, vertical longlines which possess hooks as low as possible maximize their catch within a short soaking time where fish loss is decreased. The present study suggests that vertical longlines with a small number of hooks with short vertical intervals on each center line must be used with a short soaking time for better resource utilization and protection.

The simulation also suggests that a longline gear maximizes catch with less fish loss at short soaking time in richer fishing grounds. Under such circumstances long soaking is nonsensical, and consequently, only a small number of lines can be used in a short time. This implies that set line fishing gear has a marginal advantage, for example in comparison to hand lining, in good fishing grounds. This reveals why longlining has been adapted to run through fishing grounds. In less-developed fishing grounds, the use of a small number of hooks over a short time is promising. With decreasing resources in a fishing ground, the optimum soaking time is prolonged with descending probability of catch per hook. This situation perhaps forced the use of a greater number of hooks in order to maintain the total catch. It must be noted, however, that increase of fishing with increased fish loss may accelerate the decrease of resources. This possibly illustrates the historical background for using a larger number of hooks with longer soaking through the development of most longline fishing.

The above hypothesis has implications for the assessment of applicability and feasibility for longlining in developing countries of which most coastal waters have not been commercially fished yet. Technical transfers to in- troduce longline fishing to coastal fisheries in developing countries are quite common, however, this may exhaust resources not due to larger catches but due to injury of unharvested fish under water.

The genuine needs of longlining and the influence of the gear on future resource use must, therefore be carefully evaluated through technical cooperation for fisheries extension in developing countries. Assessment of injury of unharvested fish must provide a basis for the study on unaccounted mortality which is a key concern in view of the world-wide trend toward responsible fisheries. ${ }^{* 3}$

Acknowledgments This is the final report on the research project supported by the University of Papua New Guinea. Many thanks are extended to staff members and students of the Biology and Motupore Island Research Departments of the University who helped in field work for many years.

\section{References}

1) T. Matsuoka, J. Kasu, K. Tharmaseelan, and H. Nagaleta: Preliminary Report on the Feasibility Study for Vertical Longline Fishing in Deep Reef Waters, University of Papua New Guinea, Port Moresby, 1989, pp. 1-21.

2) T. Matsuoka, J. Kasu, K. Tharmaseelan, H. Nagaleta, J. Aitsi, and T. Ito: Progress Report on the Feasibility Study for Vertical Longline Fishing in Deep Reef Waters, University of Papua New Guinea, Port Moresby, 1990, pp. 1-20.

3) T. Matsuoka: Fish Catching Mechanism in Vertical Longline Fishing, in "The Second Asian Fisheries Forum" (ed. by R. Hirano and I. Hanyu), Asian Fisheries Society, Manila, 1990, pp. 801-804.

4) T. Matsuoka, J. Kasu, and H. Nagaleta: Capture Process in vertical longline fishing. Nippon Suisan Gakkaishi, 58, 213-222 (1992).

5) Y. Yamaguchi and $H$. Kobayashi: Catch Tendency of Tuna Long Lines Fishery in Ocean and Its Consideration. Jour. Fac. Fish. Pref. Univ. Mie, 7, 2371-254 (1968) (in Japanese).

6) N. Hirayama: Studies on the Fishing Mechanism of Tuna LongLine-IV. Theoretical Analysis of Fishing Effectiveness of the Gear. Nippon Suisan Gakkaishi, 35, 635-640 (1969) (in Japanese).

7) T. Shimamura and H. Soeda: The Change of Catch of Tuna LongLine Depends on Soaking Time and Soaking Time Zone of Gear. Nippon Suisan Gakkaishi, 45, 1081-1084 (1979) (in Japanese).

8) M. Ogura, T. Arimoto, and Y. Inoue: Influence of the Immersion Time on the Hooking Rate of a Small Bottom Long-Line in Coastal Waters. Nippon Suisan Gakkaishi, 46, 963-966 (1980) (in Japanese).

9) T. Arimoto, M. Ogura, and Y. Inoue: Catch Variation with Immersion Time of Gear in Coastal Set-Line. Nippon Suisan Gakkaishi, 49, 705-709 (1983) (in Japanese).

10) T. Arimoto: Catch Variation with Operation Time in Coastal Setline. Nippon Suisan Gakkaishi, 49, 1045-1048 (1983) (in Japanese).

11) M. I. Muoneke and W. M. Childress: Hooking Mortality: A Review for Recreational Fisheries. Rev. Fish. Sci., 2, 123-156 (1994).

\footnotetext{
${ }_{3}^{3}$ T. Inoue, Y. Matsushita, and F. Chopin: World-wide trends toward conduct of responsible fishery, presentation at the spring forum of the Japanese Society of Fisheries Science in 1994.
} 